\title{
Processing instruction: Learning complex grammar and writing accuracy through structured input activities
}

\author{
Sima Modirkhamene*, Aram Pouyan, and Parviz Alavinia \\ Department of English Language and Literature, Urmia University, Urmia, West Azarbaijan, Iran
}

\begin{tabular}{|c|c|}
\hline \multirow{2}{*}{\multicolumn{2}{|c|}{$\begin{array}{l}\text { ABSTRACT } \\
\text { Aimed to change the way input is perceived and processed, processing instruction (PI) tends to } \\
\text { help learners focus on particular grammatical forms and alter their inappropriate processing } \\
\text { problems so that they make a better form-meaning connection. As an attempt to extend the } \\
\text { existing research on the use of PI, the present study was carried out to examine } 40 \text { elementary } \\
\text { EFL learners' grammatical achievement having been exposed to PI-based structured input } \\
\text { activities. Two groups of learners, namely, PI (n = 20) and traditional instruction (TI, n= 20) } \\
\text { were instructed the simple past tense -ed using PI-guided structured input activities and the } \\
\text { conventional deductive method, respectively. Findings obtained from a set of interpretation and } \\
\text { production tasks in pre- and post-test stages (immediate and delayed) revealed the superiority of } \\
\text { the PI group both in the short term and the long run when compared to their peers instructed } \\
\text { through the conventional deductive approach. Furthermore, within-group comparisons revealed } \\
\text { some variation in participants' performance in interpretation vs. production tasks. The } \\
\text { discrepant findings in the production against interpretation tasks were also confirmed by what } \\
\text { we obtained from the attitude survey; indicating that although the learners appreciated the } \\
\text { effective role of PI in their results of attitude survey, confirming learners' appreciation of the } \\
\text { effective role of PI in their comprehension of the target structure, they were not very positive to } \\
\text { the production tasks. It is concluded that different stages of comprehension and production in } \\
\text { second language development, reflected as the general proficiency of the learners, potentially } \\
\text { differ in terms of drawing learners' attention to target structures more specifically when the } \\
\text { tasks (e.g., production) are more cognitively demanding. } \\
\text { Keywords: interpretation, level of proficiency, processing instruction, processing strategies, } \\
\text { production, structured input }\end{array}$}} \\
\hline & \\
\hline $\begin{array}{c}\text { Revised: } \\
\text { 9 January } 2018\end{array}$ & \\
\hline $\begin{array}{l}\text { Final Proof Received: } \\
28 \text { May } 2018\end{array}$ & \\
\hline & \\
\hline
\end{tabular}

\section{INTRODUCTION}

In the last thirty years, we have witnessed an evolution in classroom research investigating the effects of different types of grammar instruction on second language acquisition (see Nassaji \& Fotos, 2004 for a full review). Within this research framework, another relevant question regarding the role of grammar instruction is whether it would be more useful when provided via one modality versus another (i.e., comprehension vs. production, Ellis, 2003).

Inspired mainly by Schmidt's (1993) Noticing Hypothesis, VanPatten (1996) argues that a type of focus on form, namely, 'processing instruction'(PI) helps L2 learners to notice and process target linguistic features via comprehension practice. It might be more effective than that which directs learners to the often 
premature production of language. PI is a type of approach in teaching language form based on the strategies of learners (VanPatten \& Cadierno, 1993). It consists of an explicit part based on a default inputprocessing problem and an implicit task-based part in the form of structured input tasks developed mainly to draw the attention of learners'. The structured input activities (SIA) presented in two forms of task types, namely, referential and affective are the main components of the processing instruction that are learner-centered activities and keep psycholinguistic processing mechanisms in mind. The input-based referential activities, in line with Schmidt's (1994) Noticing Hypothesis, consist of mainly enhanced 'noticing' and 'noticing-the-gap' activities that direct learners' attention to form during a communicative activity and lead learners to notice the target structure to complete the meaning of the activity. On the other hand, guided by such theoretical positions as sociocultural theory (e.g., Lantolf, 2000) and skill learning theory (Anderson, 1993), the output-based affective tasks attempt to direct learners to practice the target structure by relating it to their own experiences.

The effects of such form-meaning-based, attentiondirecting intervention in teaching the structure and grammatical morphology of language has been examined through a number of past experimental research studies (e.g., Farley, 2004; Kim \& Nam, 2017), VanPatten, 1996; VanPatten \& Uludag, 2011). The findings that can be drawn from this line of research are that these classroom studies have pinpointed that learners who receive a PI benefit in their ability to process input (interpretation tasks). However, its effectiveness concerning learners' ability to access the target feature when performing production tasks that require more significant cognitive loading has not been sufficiently established.

Due to its vital role in second language development, the concept of PI has attracted the attention of many researchers and those working in the field of second language teaching. Research on PI has explored the impact of this pedagogical intervention in shifting how L2 learners process the linguistic feature $e d$. The effects of PI, traditional instruction and meaning output-based instruction on the English simple past tense acquisition (Benati, 2005). The data were obtained from two different secondary schools (aged 12-13 years old) in China and Greece with Chinese and Greek native speakers, respectively. The results from the study showed that on the interpretation task both Chinese and Greek PI groups made more significant progress compared to the other instructional groups, which made no significant improvements. However, on the written production task, all treatment groups made equal gains (Benati, Lee, \& Houghton, 2008; Benati \& Schwieter, 2017). It means that, as Marsden and Chen's (2011) query revealed, production part of the SIA that is more cognitively demanding may not yield the same results across learners at differing stages (e.g., proficiency, age, ...) of learning.
It is also approved by the outcomes of another study by Benati and his colleagues. The study by Benati and Angelovska (2016) explored the effects of task demands on the German learners' ability to interpret and produce English past tense forms considering the effect of age within the PI research framework. For this purpose, two age groups of 10 -year-olds $(\mathrm{N}=36)$ and young adults (26 years old, $\mathrm{N}=13$ ) took part in the study. To evaluate the effect of cognitive task demands, the researchers included a second interpretation task to see if the age groups could process the structure with similar success rates in a more cognitively demanding task. The task was made more complicated by the use of present perfect tense which would challenge German learners of English in clarifying pastness with regard to their L1. The results indicated the beneficial role of PI in bringing about higher performance in form-meaning connections. Although both young and adult participants achieved higher gains in interpretation tasks, the latter group outperformed young learners in their production tasks, a finding which Benati et al. relate to the cognitive load of the tasks.

In another context, Baleghizadeh and Saharkhiz (2013) investigated the effectiveness of processing instruction as opposed to traditional deductive exercisebased intervention (TI) in teaching English derivational affixes to 101 lower-intermediate EFL learners. In recognition tasks, PI and TI groups outperformed the non-intervention group, but they did not outperform one another. In production, TI outperformed the other groups, while the other groups did not outperform one another. The authors attributed these results to the limited capacity of TI intervention in the promotion of learning compared to PI, but this capacity is shown to be retainable. Baleghizadeh and Saharkhiz (2013) recommended further studies before drawing any conclusions about the transferability of PI to output activities.

Measuring the extent to which task demands correlate with L2 development in previous research is still mixed. Otherwise stated, among the several studies carried out in this area, the issue that has received relatively less attention and has produced mixed results is whether interpretation and production tasks differ regarding the direction of attention to target structures. It is specifically of significance as the different levels of comprehension and production in the language, reflected as the general proficiency may have the potential of affecting the success of the processing instruction differentially. According to VanPatten (2004, 2007), proficiency level is a crucial factor determining the availability of processing resources. If learners are at a lower level of proficiency, one may wonder whether their attention can be effectively drawn to the target structures using the structured input activities. More specifically, there are still unanswered questions, within the processing instruction research framework, about the effect of PI on the productive ability of EFL learners and whether such effects would retain over time. Therefore, the present study sought to 
address this gap and was carried out to investigate the comparative effect of PI as opposed to traditional deductive exercise-based intervention (TI) on elementary EFL learners' learning of past tense -ed structure. It is presumed that learners at the elementary level would benefit from processing instruction since it both directly and indirectly engages them in grammatical learning. Moreover, this study looked into the distinctive effect of interpretation and production tasks in PI; it is expected that production tasks would cause challenge to elementary level learners regarding their task demand and task complexity compared to interpretation tasks that require only a receptive knowledge. Task complexity, defined as "the result of the attentional memory, reasoning, and other information processing demands imposed by the structure of the task on the language learner" (Robinson 2001, p. 29) warrants further attention in PI studies. Finally, learners' attitudes to the instruction were also explored in this study. Accordingly, the following research questions were proposed:

1. Is there a significant difference between the immediate and long-term effect upon elementary learner's interpretation vs. production of past tense -ed form of processing instruction and traditional instruction?

2. What are the attitudes of learners toward processing instruction?

\section{METHOD \\ Participants}

Forty female elementary EFL learners with similar English language learning background were conveniently sampled from a total of 51 learners. Then, the participants were assigned randomly into two treatment groups $(n=20$ in each), with one of them receiving traditional instruction (TI) and the other group receiving processing instruction for past tense grammatical structure. All the participants who are aged from 15-20 had been exposed to English in the classroom context, and none enjoyed any experience of visiting an English speaking country. Participants' proficiency level was assured to be the same according to the standard placement test of the language school from which the participants were selected.

\section{Instruments}

For the study to smoothly run forward and to accomplish its expected objectives, a number of instruments briefly explained below were taken into account. An institutionalized proficiency test, a set of interpretation and production tasks applied in pre and posttests, and an attitude questionnaire were all utilized during the study.

\section{The proficiency test}

The in-house proficiency test that was used to establish homogeneity among the participants attempted to tap into learners' language skills. The first section measured listening comprehension and included 20 multiplechoice items. The second section measured reading comprehension with eight reading passages followed by multiple-choice items. In the last part, named as language use, learners were asked to select one correct answer that fitted best in the blanks. This section aimed at testing participants' grammatical capabilities. The proficiency test enjoyed a good level of reliability $(\alpha=$ .86) calculated using Cronbach's alpha.

\section{Processing instruction materials}

The package was developed based on the guidelines for the development of structured input activities presented in VanPatten and Sanz (1995) included explicit instruction about the target grammatical structure (i.e., past tense -ed), and a set of structured input activities. Explicit instruction encompassed information about the processing principles, and structured input activities consisted of an equal number of referential and aff ective activities. Figure 1 shows the examples of referential and affective activities used in the study.

\section{Referential}

You will hear ten sentences, and you need to identify if the action is taking place now (present) or has already taken place (past).

1. I study English.

2. I talked with my teacher.

Present $\square$ Past

(8 more items with the same structure)

\section{Affective}

Listen to your teacher saying a number of statements and determine if you did the same thing in the weekend.

1. I played with my dog.

Me too

I did not. $\square$

2. I helped my mother clean the home. Me too

I did not.

(8 more items with the same structure)

Figure 1. Processing instruction materials activities 
Tests (pretest, immediate and delayed posttests) Participants received the pretests one week before the start of the instructional treatment. Two forms of tests, that is, one interpretation task and one written production task were developed (Benati, 2005). The interpretation task (see Appendix A) comprised 20 sentences (10 distracter items in the present regular form). The participants were asked to listen to the sentences read by the teacher and pinpoint (interpret) the correct sentences in terms of the structure being focused. The interpretation task did not have a repetition as we opted to measure real-time comprehension. The scoring of interpretation task followed a binary criterion, with an incorrect response receiving 0 point and the correct response getting 1 point.

The written production task (Appendix B) was designed with the purpose of evaluating participants' ability to produce correct sentences using the target structure in both pretest and posttest. The learners were asked to look at 3 pictures and to produce a sentence for each of the pictures using the grammatical point provided. The production tasks were subject to the same scoring procedure used in the interpretation task (correct form 1 score; incorrect form 0 score). The production task provided learners with enough time to monitor and write their answers.

These tests had the same format and number of items, but different questions and different sentences with different verbs were used for the immediate and delayed posttests. It is important to note that there was a three-week time interval between the immediate and delayed posttests. Acceptable estimates of validity (factor loading over 60\%) and reliability (Cronbach's Alpha) were obtained for the pretest $(\alpha=.70)$, posttest $(\alpha=.72)$ and delayed posttest $(\alpha=.68)$.

\section{Attitude questionnaire}

The attitude questionnaire elicited PI group participants' opinions about the effectiveness of the PI instructional method. Eight Likert scale questions, whose responses varied from 1 (strongly disagree) to 5 (strongly agree), were included in the survey. The questions asked learners if they thought that the instruction was a beneficial and helpful method for improving their grammatical knowledge. The participants were asked to provide their opinions about the instruction at the end of the survey and write down any further comments through two open-ended items.

\section{Procedure}

Homogeneity of the participants was first assured through the use of the proficiency test. The PI group was exposed to the processing instruction for three consecutive sessions (two hours per day) on the target structure. In both groups, the regular classroom teacher (i.e., the researcher) who was familiar with how to carry out the instructional treatment also acted as the instructor as well as the facilitator. The learners in the PI group first received explicit instruction about the target feature and then were involved in the structured input activities. The structured input activities asked the learners to identify if the action was taking place in the present or had already taken place in the past.

Another package of materials (see Appendix C) was designed for the TI (traditional instruction) group which combined the mechanical activities and communicative practice. In the TI classroom, learners were presented with both mechanical and meaningful activities that required learners to use past tense to deliver meaning without any conscious attention to the target structure, that is past tense -ed.

After the instructional period, the researchers conducted the immediate post-test and the delayed post-test (within a three-week time interval) including both the interpretation and production tasks

\section{RESULTS}

Having assured the assumption of normality in data collection stages including the pre-, immediate, and delayed posttests $(p>0.05)$, the researchers ran a series of independent samples $t$-tests to obtain logical answers to each research question. Before treatment, a t-test was initially used to ascertain the homogeneity of the participants in the pretest. The results between the PI and TI groups' means indicated no significant differences neither in interpretation tasks $(t(38)=.415$, $\mathrm{p}=.68)$ nor in the written production tasks $(\mathrm{t}(38)=$ $.549, \mathrm{p}=.45)$ before instructional intervention was initiated.

The pretest scores for the written production task revealed no significant differences between PI and TI group-means before the instruction.

Table 1 summarizes descriptive results obtained in the three stages of data collection. The results showed that only the PI group made progress from pretest to both immediate and delayed posttest stages in their interpretation of the accurate past tense -ed structure. Independent samples t-test checked whether these differences were significant (Table 2, and Table 3).

As for the first research question, the dependent and independent variables were the interpretation scores in two PI and TI treatment conditions.

Table 1. Descriptive statistics: Participants' performance in interpretation tasks

\begin{tabular}{|c|c|c|c|c|c|c|c|}
\hline Variable & $\mathrm{N}$ & $\begin{array}{c}\text { Pre-test } \\
\text { Mean }\end{array}$ & SD & $\begin{array}{c}\text { Post-test } \\
\text { Mean }\end{array}$ & SD & $\begin{array}{c}\text { Delayed post-test } \\
\text { Mean }\end{array}$ & SD \\
\hline PI & 20 & 2.60 & .99 & 4.70 & 1.49 & 3.80 & 1.47 \\
\hline TI & 20 & 2.45 & 1.27 & 3.10 & 1.37 & 2.85 & 1.22 \\
\hline
\end{tabular}


Indonesian Journal of Applied Linguistics, 8(1), May 2018

Table 2. T-test results for PI and TI: test interpretation task performance (Immediate post-test)

\begin{tabular}{|c|c|c|c|c|c|c|c|c|c|c|}
\hline & & \multicolumn{2}{|c|}{$\begin{array}{l}\text { Levene's Test } \\
\text { for Equality of } \\
\text { Variances }\end{array}$} & \multicolumn{7}{|c|}{ t-test for Equality of Means } \\
\hline & & \multirow[t]{2}{*}{$\mathrm{F}$} & \multirow[t]{2}{*}{ Sig. } & \multirow[t]{2}{*}{$\mathrm{T}$} & \multirow[t]{2}{*}{ df } & \multirow{2}{*}{$\begin{array}{l}\text { Sig. (2- } \\
\text { tailed) }\end{array}$} & \multirow{2}{*}{$\begin{array}{c}\text { Mean } \\
\text { Difference }\end{array}$} & \multirow{2}{*}{$\begin{array}{l}\text { Std. Error } \\
\text { Difference }\end{array}$} & \multicolumn{2}{|c|}{$\begin{array}{l}95 \% \text { Confidence Interval } \\
\text { of the Difference }\end{array}$} \\
\hline & & & & & & & & & Lower & Upper \\
\hline \multirow[t]{2}{*}{ Delayed } & $\begin{array}{l}\text { Equal } \\
\text { variances } \\
\text { assumed }\end{array}$ & .023 & .879 & 3.532 & 38 & .001 & 1.60000 & .45306 & .68283 & 2.51717 \\
\hline & $\begin{array}{l}\text { Equal } \\
\text { variances not } \\
\text { assumed }\end{array}$ & & & 3.532 & 37.746 & .001 & 1.60000 & .45306 & .68263 & 2.51737 \\
\hline
\end{tabular}

Table 3. T-test results for PI and TI: interpretation task performance (Delayed post-test)

\begin{tabular}{|c|c|c|c|c|c|c|c|c|c|c|}
\hline & & \multicolumn{2}{|c|}{$\begin{array}{l}\text { Levene's Test } \\
\text { for Equality of } \\
\text { Variances }\end{array}$} & \multicolumn{5}{|c|}{ t-test for Equality of Means } & \multirow{2}{*}{\multicolumn{2}{|c|}{$\begin{array}{l}\text { 95\% Confidence Interval } \\
\text { of the Difference }\end{array}$}} \\
\hline & & \multirow[t]{2}{*}{$\mathrm{F}$} & \multirow[t]{2}{*}{ Sig. } & \multirow[t]{2}{*}{$\mathrm{T}$} & \multirow[t]{2}{*}{$\mathrm{df}$} & \multirow{2}{*}{$\begin{array}{l}\text { Sig. (2- } \\
\text { tailed) }\end{array}$} & \multirow{2}{*}{$\begin{array}{c}\text { Mean } \\
\text { Difference }\end{array}$} & \multirow{2}{*}{$\begin{array}{l}\text { Std. Error } \\
\text { Difference }\end{array}$} & & \\
\hline & & & & & & & & & Lower & Upper \\
\hline \multirow[t]{2}{*}{ Delayed } & $\begin{array}{l}\text { Equal } \\
\text { variances } \\
\text { assumed }\end{array}$ & 1.675 & .203 & 2.217 & 38 & .033 & .95000 & .42843 & .08269 & 1.81731 \\
\hline & $\begin{array}{l}\text { Equal } \\
\text { variances not } \\
\text { assumed }\end{array}$ & & & 2.217 & 36.790 & .033 & .95000 & .42843 & .08175 & 1.81825 \\
\hline
\end{tabular}

The results demonstrated that there was a significant effect for processing instruction in both immediate posttest $(\mathrm{t}(38)=3.53, \mathrm{p}=.001)$ and delayed posttest $(t(38)=.203, \mathrm{p}=.033)$. This result is in line with those of descriptive statistics showing the superiority of PI $(\mathrm{M}=4.70, \mathrm{SD}=1.49)$ over $\mathrm{TI}(\mathrm{M}=$ $3.10, \mathrm{SD}=1.37)$ in the immediate and delayedposttests (PI $(\mathrm{M}=3.80, \mathrm{SD}=1.47), \mathrm{TI}(\mathrm{M}=2.85, \mathrm{SD}=1.22)$, respectively. The results of $t$-test clearly point to the effectiveness of processing instruction in bringing about enhanced comprehension of past tense -ed among elementary EFL learners.

\section{Written production task}

As for the second research question, we dealt with participants' production scores in two PI and TI treatment conditions in the immediate and delayed posttests.

The descriptive statistics summarized in Table 4 indicates that only the PI groups made some progress from pretest to posttest, although the difference between the two groups was not meaningful.

The results obtained from the independent samples $t$-test (see Tables 5, and 6) pointed to a non-significant effect of instruction in both immediate posttest $(\mathrm{t}(38)=$ $1.39, \mathrm{p}=.17)$ and delayed posttest $(\mathrm{t}(38)=.695, \mathrm{p}=$ .49) as regards production. This result corresponds to those of descriptive statistics (Table 4) showing minute differences between PI $(\mathrm{M}=3.40, \mathrm{SD}=1.35)$ and $\mathrm{TI}$ $(\mathrm{M}=2.80, \mathrm{SD}=1.36)$ in immediate and delayed posttests (PI $(\mathrm{M}=2.70, \mathrm{SD}=1.12)$, $\mathrm{TI}(\mathrm{M}=2.45, \mathrm{SD}=$ 1.14).

Table 4. Descriptive statistics: Participants' performance in production tasks

\begin{tabular}{lccccccc}
\hline Variable & $\mathrm{N}$ & $\begin{array}{c}\text { Pre-test } \\
\text { Mean }\end{array}$ & $\begin{array}{c}\text { SD } \\
\text { Mean }\end{array}$ & $\begin{array}{c}\text { Post-test } \\
\text { MD }\end{array}$ & $\begin{array}{c}\text { Delayed post-test } \\
\text { Mean }\end{array}$ & SD \\
\hline PI & 20 & 2.45 & 1.35 & 3.40 & 1.35 & 2.70 & 1.12 \\
TI & 20 & 2.15 & 1.13 & 2.80 & 1.36 & 2.45 & 1.14 \\
\hline
\end{tabular}

Table 5. T-test results for PI and TI: production task performance (Immediate post-test)

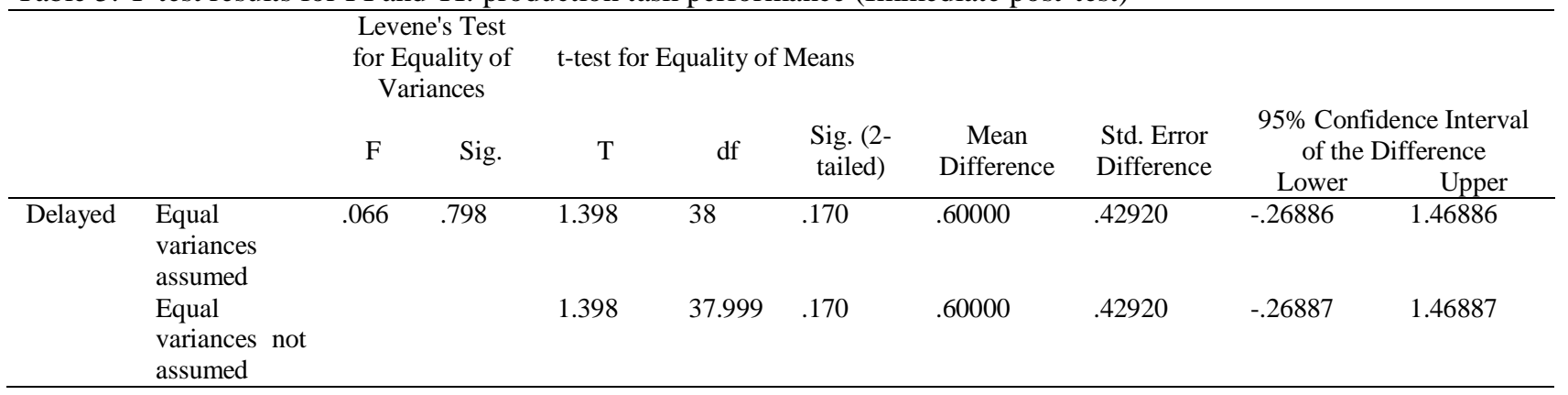


Table 6. T-test results for PI and TI: production task performance (Delayed post-test)

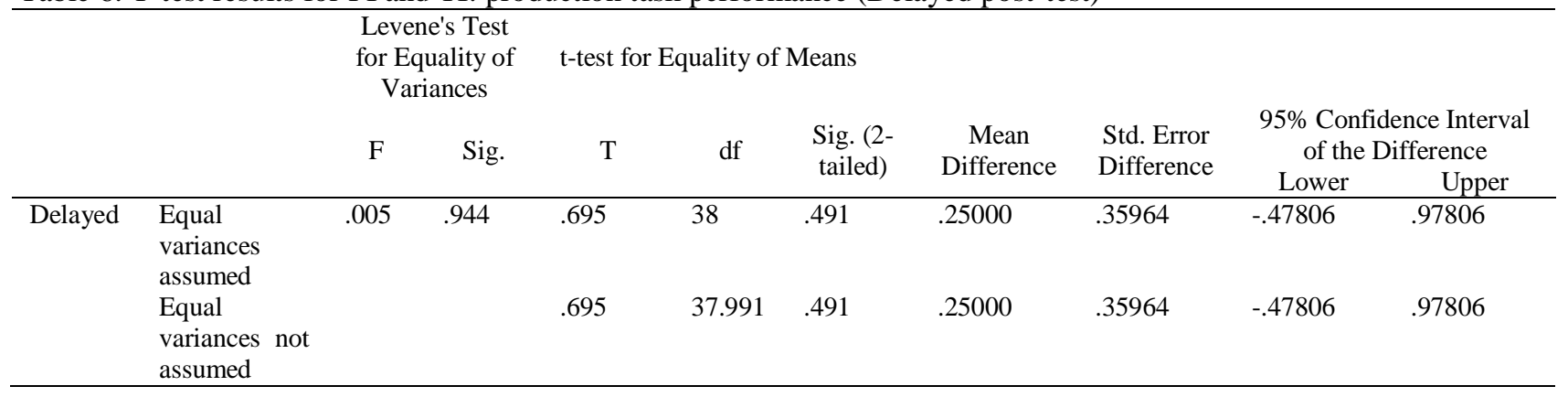

The above-mentioned statistical analyses point to the superiority of PI over TI in the interpretation of the past-tense -ed among elementary learners over time, while these two groups did not turn out to be different regarding their performance in the production tasks.

\section{Attitude}

It needs to be noted that the significance ascribed to either of these approaches might be partly bound to be the function of the inherent specificities of a specific educational setting as well as the learners' perceptions towards it. Thus, to understand the effectiveness of PI better, the researchers asked the participants to fill out an attitude survey with 8 Likert-scale items and two open-ended questions. The results of the questionnaire are depicted in Figure 2.

Considering the prevalence of explicit grammar teaching in most EFL contexts, the limited number of language lessons and restricted out-of-class exposure, the shift from traditional explicit instruction to processing instruction seems to be inevitable. Confirming this, the total positive attitudes of participants to their experience with PI prove the effectiveness of this instruction type for elementary language learners. More specifically, more than half of the participants strongly agreed with the appropriate instruction $(52 \%)$, the usefulness of explanations about incorrect strategies $(57 \%)$, effectiveness of PI activities $(63 \%)$, enjoyable grammar learning experience $(62 \%)$, and the helpful role of affective structured input activities in linking the learning of target structure to their real-life experiences $(59 \%)$. However, learners were not clearly inclined towards the task effectiveness, that is, the use of interpretation and written production tasks. The results of the statistical analysis revealed that PI learners could not outperform their TI peers in their production of the target structure. This is confirmed in the survey since the difficulty of the tasks was a conflicting issue. The results of the open-ended questions in the survey indicate that some participants were not able to use the newly learned structure in written practice. For example, a learner declared that "I understand, but I cannot write it. It is difficult for me." Some other learners provided similar comments indicating the inefficiency of written practice for elementary level learners. This tendency is reflected in learners' general preference of PI over TI since nearly half $(49 \%)$ of the participants agreed with PI, which might have been affected by the difficulty of production task for learners.

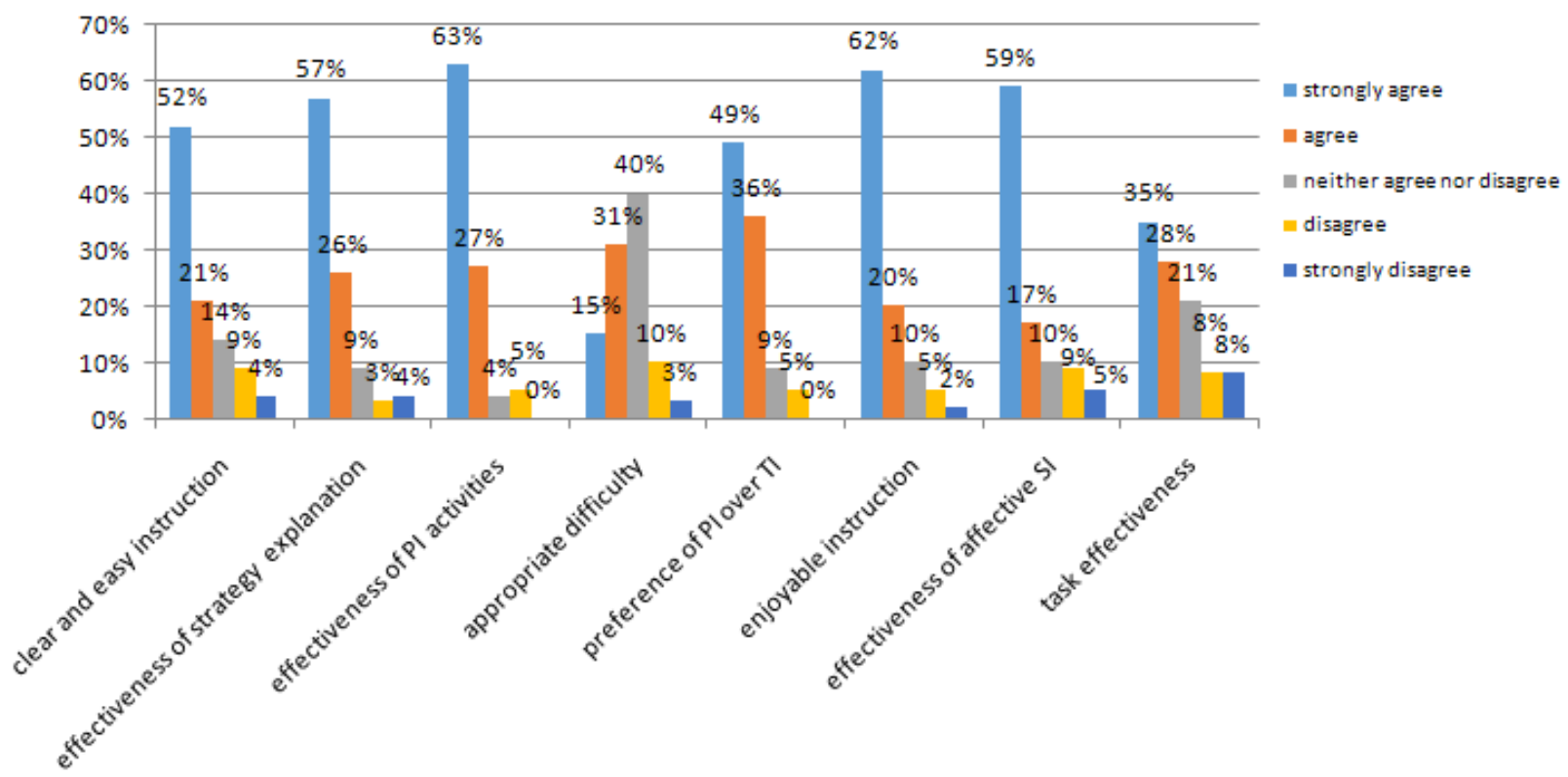

Figure 2. Learners' attitude to PI practice

Copyright (C) 2018, IJAL, EISSN 2502-6747 


\section{DISCUSSION}

Given that there are limitations in the processing instruction research base (Cheng, 2004), the main goal of the study was to compare the effects of processing instruction and traditional instruction on learners' acquisition of the past tense -ed structure. An additional aim of the present study was to examine the possible effects of processing instruction treatment on learners' ability to interpret and produce sentences containing English past tense forms.

Two classroom practices were conducted to address the research questions of this study. Overall, the results provided the following new evidence from elementary learners on the effectiveness of processing instruction:

1. EFL learners exposed to processing instruction improved their ability to interpret sentences consisting of English past tense. It means that PI with explicit instruction and structured input activities was effective in drawing learners' attention to the correct selection of past tense forms and their general comprehension. These findings replicate current research on the role of explicit instruction in PI, revealing an advantage for it with the target form (e.g., Henry, Jackson \& Dimidio, 2017).

2. EFL learners receiving processing instruction did not improve their ability to use the past tense forms in their writing. It indicates that the cognitively demanding productive ability of elementary learners was limited so that they could not embed their noticed structure in their production.

3. Iranian EFL learners receiving the processing instruction, over time, outperformed their TI peers in interpreting sentences containing past tense. It means that PI is an effective instructional practice due to its capability in helping learners make form-meaning connections for the developmental acquisition of language.

The findings, on the whole, from the PI and TI instructions approved the researchers' prediction that learners exposed to processing instruction show progress in their ability to interpret sentences including the past tense forms. The findings indicated that processing instruction could potentially modify the way L2 learners of English process sentences containing past tense structures. This is in line with previous studies (e.g., Baleghizadeh, \& Saharkhiz, 2013; Lee \& Benati, $2007 \mathrm{a} ; 2007 \mathrm{~b})$ which investigated the efficiency of enhanced structured input activities employing past tense in the second language. The results of these studies pinpointed that the structured input practice changed L2 learners' inefficient processing strategies and assisted the learners to analyze past tense accurately.
Furthermore, the outcomes evidence Schmidt (1994), and VanPatten's (1996) concept of conscious attention - 'noticing' - to linguistic structures of the language in input which they consider as a crucial prerequisite for second language acquisition.

However, the results demonstrate that this approach was not effective with regard to improving learners' production skill. Therefore, although processing instruction is responsible for the increased rate of processing, it is possibly not conducive to any rate of accuracy in production for elementary learners. Results of the present study contradict previous research evidence which postulates positive effects for PI at production and discourse levels (Benati, 2001; Cheng 2002, 2004; Izumi, 2002; Song \&Suh, 2009; VanPatten \& Sanz, 1995). Written and oral production tasks in these studies were developed in VanPatten and Sanz's (1995) study. Benati(2001) also developed an oral discourse level production task, and Cheng (2002, 2004) created a guided composition written task. The overall findings from these four studies -that probably have not taken into account learners' developmental stage of language learning (i.e., proficiency)- showed that processing instruction effectively helped learners alter inappropriate processing strategies even when measured on less controlled tasks and discourse level production tasks.

A recent study by Benati and Angelovska (2016), too, indicates the beneficial role of PI in bringing about higher performance in form-meaning connections. Although both young and adult participants achieved higher gains in interpretation tasks, the latter group outperformed young learners in their production tasks, a finding which Benati et al. relate to the cognitive load of the tasks. It seems that different stages of comprehension and production in second language development, reflected as the general proficiency of the learners, potentially differ regarding the direction of learners' attention to target structures more specifically when the tasks (e.g., production) are more cognitively demanding.

The discrepant findings in the production against interpretation tasks in the current investigation are confirmed by what we obtained from the attitude survey, indicating that although the learners appreciated the effective role of PI in their comprehension of the target structure, they were not very favorable to the production tasks. They may have experienced difficulties with the production of a recently learned linguistic feature. These results, taken together, seem to imply that the unique role of processing instruction in L2 learning is to facilitate paths to target-like language production. It would, however, be useful in a classroom to devise and use this type of instruction.

\section{CONCLUSION}

This study has pinpointed that processing instruction can be successfully implemented using input-based tasks that motivate beginner learners and also that, in 
some respects, it is more effective than traditional instruction. The analysis of the responses to tasks and the survey analyses indicated that the learners were actively engaged in the input-based tasks. Based on the results of the pretest which indicated participants' unfamiliarity, to some extent, with the past feature, it is possible to conclude that the PI students learned the target feature with conscious attention while performing the tasks. The point is highly possible given their nearzero competence of the target structure in the pretest and their higher performance in the interpretation task. It is consistent with how Van Patten considers the effect of PI: this consists of more than just comprehending input; learners should devote attention to linguistic form, which necessitates modifying the natural way in which they process input. However, the non-significant difference between PI and TI in the production task implies that PI learners did not manage to use the recently noticed past tense -ed in their productions, justified by their level of proficiency. Incapability of producing the target structure does not preclude the possibility of learners' noticing of the forms they acquire.

The results of this query suggest that tasks need to be highly contextualized. As elementary learners are inherently more inclined towards incidental learning rather than intentional learning, it is crucial to present tasks that establish contexts which are familiar to the specific learners (Shintani \& Ellis, 2010). This contextualization can be provided using the affective structured input activities. The interpretation tasks and also the written production tasks are suggested to be introduced using familiar categories (i.e., celebration, sport, and car repair) involving concepts that are familiar for elementary learners.

Also, the task requirements need to be simple and clear enough for elementary learners to comprehend. All the tasks used in the processing instruction are recommended to employ simple procedures which enable the learners to engage in the tasks easily.

Also, tasks need to require the learners to work individually and in the group. In order to maximize the class time and to sustain the motivation of the learners, the tasks should be designed to lessen the waiting time for learners. The processing instruction can provide activities and explicit instruction on paper for each student, which enables learners to work on the tasks individually but also benefit from the collective responses of the whole class.

The study raises a number of issues relating to research on grammar acquisition. Studies of various other linguistic features are needed to understand the relationship between the intrinsic difficulty of different grammatical features and grammatical acquisition. The influence of individual learner factors such as language aptitude and working memory on the acquisition resulting from PI and TI should also be investigated. This study examined the effect of PI only on elementary level learners, and as discussed above, the level of the participants was a highly influential factor in limiting their productive capacities. Therefore, the partly supported results of this study need to be complemented by future investigations. To get a more reliable and complete picture of PI, future studies are encouraged to explore the success of learners from proficiency levels in recognizing and using different target structures.

\section{REFERENCES}

Anderson, J. R. (1993). Rules of the mind. Hillsdale, NJ: Erlbaum Associates.

Baleghizadeh, S., \& Saharkhiz, A. (2013). An investigation of spoken output and intervention types among Iranian EFL learners. Journal of English Language Teaching and Learning, 5(2), 17-41.

Benati, A. (2001). A comparative study of the effects of processing instruction and output-based instruction on the acquisition of the Italian future tense. Language Teaching Research, 5, 95-127.

Benati, A. (2005). The effects of processing instruction, traditional instruction and meaning-output instruction on the acquisition of the English past simple tense. Language Teaching Research, 9(1), 67-93.

Benati, A., \& Schwieter, J. W. (2017). Input processing and processing instruction. In T. Angelovska and A. Hahn (ed.), L3 syntactic transfer: Models, new developments and implications (pp. 253-275). Amsterdam: Benjamins Publishing.

Benati, A., Lee, J., \& Houghton, S. D. (2008). From processing instruction on the acquisition of English past tense to secondary transfer-of-training effects on English third person singular present tense. In A. Benati \& J. Lee (Eds.), Grammar acquisition and processing instruction: Secondary and cumulative effects (pp. 88-120). Clevedon: Multilingual Matters.

Benati, S., \& Angelovska, T. (2016). The effect of processing instruction on the acquisition of English simple past tense: Age and cognitive past demands. International Review of Applied Linguistics in Language Teaching, 53(2), 249269.

Cheng, A. (2002). The effects of processing instruction on the acquisition of ser and estar.Hispania, 85, 308-323.

Cheng, A. (2004). Processing instruction and Spanish ser and estar: Forms with semantic-aspectual value. In B. VanPatten (Ed.), Processing instruction: Theory, research, and commentary (pp. 119-141). Mahwah, NJ: Erlbaum.

Ellis, R. (2003). Task-based language learning and teaching. Oxford: Oxford University Press.

Farley, A. (2004). The relative effects of processing instruction and meaning-based output instruction. In B. VanPatten (Ed.), Processing instruction: Theory, research, and commentary (pp. 143-168). Mahwah, NJ: Erlbaum. 
Henry, N., Jackson, C. N., \& Dimidio, J. (2017). The role of prosody and explicit instruction in processing instruction. The Modern Language Journal, 101, 294-314.

Izumi, S. (2002). Output, input enhancement, and the noticing hypothesis: An experimental study on ESL relativization. Studies in Second Language Acquisition, 24, 541-577.

Kim, J., \& Nam, H. (2017). The pedagogical relevance of processing instruction in second language idiom acquisition. International Review of Applied Linguistics in Language Teaching, 55(2), 93 132.

Lantolf, J. P. (2000). Second language learning as a mediated process. Language Teaching, 33(2), 7996.

Lee, J. F., \& Benati, A. (2007a). Delivering Processing Instruction in classrooms and virtual contexts: Research and practice. Equinox, London.

Lee, J. F., \& Benati, A. (2007b). The effect of structured input activities on the acquisition of two Japanese linguistic feature. In Delivering Processing Instruction in classrooms and virtual contexts: Research and practice. Equinox, London.

Marsden, E., \& Chen, H.-Y. (2011). The roles of structured input activities in processing instruction and the kinds of knowledge they promote. Language Learning, 61(4), 1058-1098.

Nassaji, H., \& Fotos, S. (2004). Current development in research on the teaching grammar. Annual Review of Applied Linguistics, 24, 126-145.

Robinson, P. (2001). Task complexity, task difficulty, and task production: Exploring interactions in a componential framework. Applied Linguistics, 22(1), 27-57

Schmidt, R. (1993). Awareness and second language acquisition. Annual Review of Applied Linguistics, 13, 129-158.
Schmidt, N. (1994). Vocabulary testing: Questions for test development with six examples of tests of vocabulary size and depth. Thai TESOL Bulletin, 6(2), 9-16.

Shintani, N., \& Ellis, R. (2010). The incidental acquisition of English plural $-\mathrm{s}$ by Japanese children in comprehension-based and productionbased lessons. Studies in Second Language Acquisition, 32, 607-637.

Song, M. J., \& Suh, B-R. (2008). The effects of output task types on noticing and learning of the English past counterfactual conditional. System, 36, 295312 .

VanPatten, B. (1996). Input processing and grammar instruction: Theory and research. Norwood, NJ: Ablex.

VanPatten, B. (2004). Input processing in second language acquisition. In B. VanPatten (Ed.), Processing instruction: Theory, research, and commentary (pp. 5-31). Mahwah, NJ: Erlbaum.

VanPatten, B. (2007). Input processing in adult second language acquisition. In B. VanPatten \& J. Williams (Eds.), Theories in second language acquisition (pp.115-135). Mahwah, NJ: Erlbaum.

VanPatten, B., \& Uludag, O. (2011). Transfer of training and processing instruction: From input to output. System, 39(1), 44-53.

VanPatten, B., \& Cadierno, T. (1993). Input processing and second language acquisition: A role for instruction. The Modern Language Journal, 77(1), 45-57.

VanPatten, B., \& Sanz, C. (1995). From input to output: Processing instruction and communicative tasks. In F.R. Eckman., D. Highland., P. W. Lee., J. Mileham., \& R. R. Weber. (Eds.), Second language acquisition theory and pedagogy (pp.169-185). Mahwah, NJ: Erlbaum. 


\section{Appendix A (the interpretation task)}

Listen to each sentence and indicate if the event occurred last week or it is an action which takes place regularly in the present.

1. I watched TV all night.

2. I live in Canada.

3. I needed a mechanic to repair my car.

4. I want to go to the dentist.

5. I closed the door.

6. They visited my party.

7. I travelled to Japan.

8. I wash her car.

9. I finished work.

10. I added milk to the cake.

11. I talked to her mum.

12. He stayed at the party.

13. I study French.

14. I played the violin.

15. I work at the library.

16. I like tomatoes in soup.

17. The storm destroyed the garden.

18. I cleaned my room.

19. I play tennis with my friend.

20. I showed my new shirt to her. 
Appendix B (written production task)

Look at the pictures and write a sentence describing what happened using one verb and one noun from the list provided.
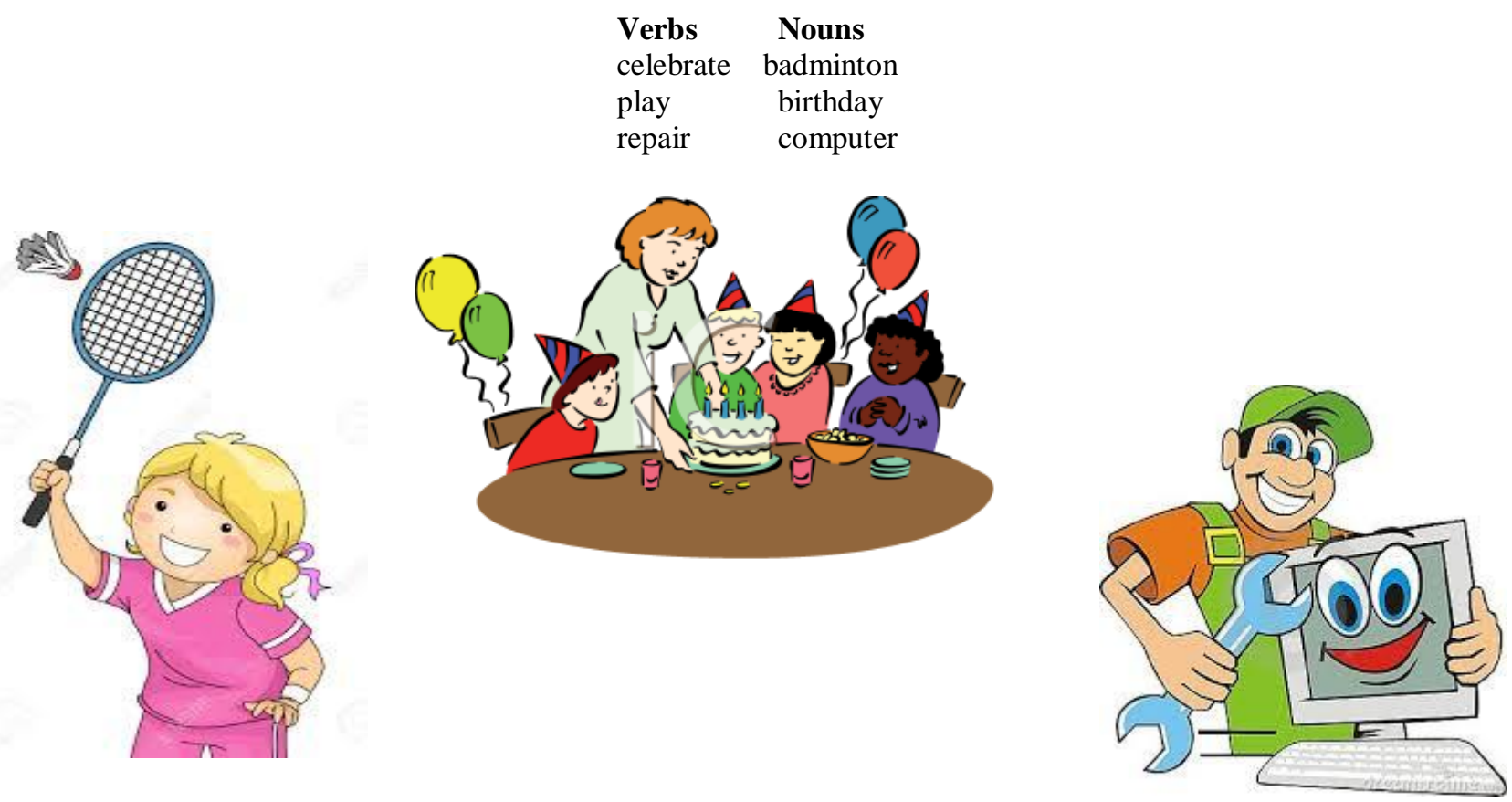


\section{Appendix C (traditional instruction tasks)}

\section{Activity A (sample)}

Put the verbs provided in the simple past tense.

1) Last week, I (visit) my uncle.

2) Yesterday, I (play) football with my friends.

3) I (travel) to Australia last year.

4) At noon, she (wash) her car.

5) Last Monday, Peter (look) for Chelsea in the shopping center.

6) I (live) in Paris two years ago.

7) Saturday, Mike (enjoy) the film in the cinema.

8) Sara (laugh) at the clown in the party.

9) John (cry) yesterday for his low score.

10) My mother (bake) the cake for my birthday.

\section{Activity B (sample)}

Make a list of 5 positive and 5 negative things that your school did for the students last year.

Last year the school...

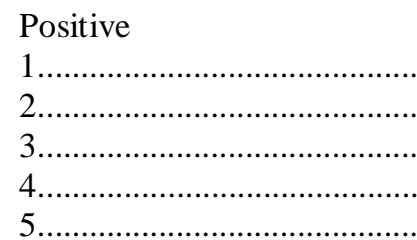

Negative

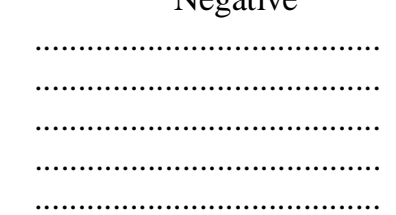

